\title{
Adenocarcinoma In Situ in Tubulovillous Adenoma
}

National Cancer Institute

\section{Source}

National Cancer Institute. Adenocarcinoma In Situ in Tubulovillous Adenoma. NCI

Thesaurus. Code C4144.

A non-invasive adenocarcinoma arising from a tubulovillous adenoma. 